\title{
Research on ecological water demand of lakes
}

\author{
Pingyu $\mathrm{Lu}^{1,3}$, Junxi Chen ${ }^{1,2}$, Huihuang Luo ${ }^{2, *}$, and Qingrui Yang $^{2}$ \\ ${ }^{1}$ Chongqing Jiaotong University, 400074 Chongqing, China \\ ${ }^{2}$ Institute of Water Ecological Environment, Chinese Academy of Water Sciences, 100038 Beijing, \\ China \\ ${ }^{3}$ Hydrology and Water Resources Survey Bureau of the Upper Yangtze River, 400025 Chongqing, \\ China
}

\begin{abstract}
With the rapid development of social economy, the development and utilization of water resources is increasing, which leads to the increasing importance of ecological water demand in wetland protection. The study of lake ecological water demand can provide theoretical basis for improving the distribution of water resources and ecosystem balance in lake wetland and establish a solid theoretical basis for the sustainable development of lake wetland ecosystem. Based on the analysis and summary of the relevant literature on wetland ecological water demand, this paper expounded the connotation of lake ecological water demandand summarized the calculation method of ecological water demand of lake type wetland in China. In addition,this paper pointed out that the research focus of lake ecological water demand mainly included the application of hydrologicalhydrodynamic-water quality and the research of water demand based on ecological protection target hydrology demand.
\end{abstract}

Keywords: Lakes; Ecological water demand; Ecological balance; Sustainable development.

\section{Introduction}

China's lakes are rich in natural resources and have a variety of ecological functions. It plays an important role in industry, agriculture, domestic water, hydropower engineering, waterway transportation, tourism development, aquaculture, mineral development and the maintenance of environmental ecological balance[1].However, in recent years, some lakes in China are faced with the problems of continuous drought, shrinking area and serious water pollution, which leads to the deterioration of the ecological environment of lakes[2].Therefore, it is necessary to ensure water amount to improve the appropriate lake water level and improve the self-purification capacity of the water area. In order to better protect the biodiversity of lakes and ecosystems and realize the sustainable development of the region as soon as possible. It is essential to carry out a quantitative analysis of the lake's ecological water demand.

\footnotetext{
*Corresponding author: luohh@iwhr.com
} 


\section{Connotation of lake ecological water demand}

Some scholars also believe that the ecological water demand of lakes refers to the amount of water that needs to be replenished every year due to the consumption of water, in order to maintain the function of lakes without damage[3].Tang Yun et al. proposed that the lake's ecological water demand is the amount of water required to meet the normal operation of the lake's ecological function, including evaporation and leakage of the water surface under specific goals[4]. Ngana proposed that the ecological water demand of lakes needed to ensure the coordinated development of social economy and ecological environment and maintain the lake ecosystem[5].

\section{Calculation method of ecological water demand in lakes}

\subsection{Water balance method}

Based on the research object of Pang Rui and others, the water requirement of maintaining the basic ecological function of the downstream lake is established[6]. We can calculate demand of ecological water for the downstream lake by using the water balance ecological water demand calculation method, which provides a scientific basis for solving the problem of lake shrinkage in the tail end of Bayin River, rationally allocating resources of water in Bayin River Basin. This method mainly considers maintaining a specific surface area, which is mainly determined by long sequence surface area frequency analysis, but the response relationship between the determined surface area and the ecological environment is less considered, and the ecological meaning of the surface area is not clear. This method is mainly suitable for lakes with small water level variation.

\subsection{Natural water level data method}

Under natural conditions, the lake water level will change year by year and interannual, thus disturbing the ecosystem. In the long-term ecological evolution, the lake ecosystem has adapted to this interference. Low water levels under natural conditions can have an impact on the ecosystem, but the impact will always remain within the elastic range of the ecosystem. Therefore, the lowest water level for many years under natural conditions is considered to be the lowest ecological water level[7].The natural water level data method takes into account the fluctuation of natural water level, and the use of natural water level statistics has reliability, but it can not be ignored that the length of historical water level data series has some limitations. When using this method, the data of typical year should be selected instead of the actual multi-year water level data.

\subsection{Frequency curve method}

The frequency curve method refers to the collection of hydrological and historical data for more than 30 years, and the frequency curve is drawn according to the monthly hydrological frequency of the lake. When Chen Changqing and Wei Cong calculated the ecological water level in Luohu Lake, they used the P-III type frequency distribution curve to fit the monthly average water level distribution of Wufangtai station, and selected the water level at $50 \%$ and $90 \%$ frequencies as the suitable ecological water level and the lowest ecological level of water, respectively. Finally, the suitable ecological water level was $23.35 \mathrm{~m}$, and the lowest ecological water level was $23.14 \mathrm{~m}$ [8]. Chen Jiang et al also used the frequency curve method to analyze and calculate the ecological water level in Poyang Lake at three different time 
scales: year, month and day, which provided scientific basis for the regulation of ecological water level in Poyang Lake[9].

\subsection{Water cycle change method}

The water exchange cycle refers to the theoretical concept of the length of time required to exchange and update all lake water once. When studying the ecological water level of Dongping Lake, $\mathrm{Yu}$ Xiaolong and others proposed to simulate and predict the important hydrological indexes such as water exchange period under the combination of multiple water sources, so as to provide scientific basis for the study of ecological water level and the maintenance of ecosystem function in Dongping Lake[10]. This is important for the scientific management of lake ecosystems, especially artificial lakes. For the health of the lake and the downstream ecosystem, the flow rate and flow rate should be controlled reasonably, and the water exchange cycle method is suitable for the closed flow lake with less human disturbance or the abundant water resources.

\subsection{Functional approach}

According to the ecological function of lake ecosystem, Liu Jingling and Yang Zhifeng put forward the following types of lake ecological water demand: lake evapotranspiration water demand, lake aquatic organisms and their habitat water demand, lake surface runoff water demand, lake surface runoff water demand[11]. According to the function of Baiyangdian ecosystem, However, this method is mainly suitable for relatively shallow lake basins and not for narrow and deep lakes. The method takes into account different functional requirements, but from the functional point of view, it is easy to cause functional overlap or omission, and the final ecological water demand is large or small.

\subsection{Analysis of lake morphology}

Lake function has a strong correlation with the amount of water entering the lake and the change of lake area.The ecological function of the lake can be expressed by the size of the lake surface.In the relation curve of lake water level and water surface area change, the lake surface area and its change rate increase with the increase of water level[12]. The advantages of this method are that the hydrological and topographic elements of lakes are considered to make the research results more reasonable and practical, and the main disadvantages are the lack of ecological meaning of lakes and the insufficient consideration of ecological needs.

In calculating the ecological water demand of lakes, because the starting point of various calculation methods is different and the diversity of lake characteristics in China, it is necessary to analyze the actual situation of lakes and the applicability, advantages and disadvantages of various calculation methods.

\section{Research hotspot of lake ecological water demand}

\subsection{Research on ecological hydrological needs based on ecological conservation objectives}

The determination of ecological protection objectives is multi-faceted and multi-angle, which is also a hot topic that many scholars are actively studying at present. In most of the previous calculation methods of ecological water demand in lakes, the ecological hydrological response relationship of ecological protection objectives is less considered[13].The 
ecological water demand of lakes should be determined by focusing on the requirements of ecological objectives, and the ecological hydrological response relationship based on ecological protection objectives is the focus of the study in the future.

\subsection{Multi-objective ecological water demand synergy}

Lakes' ecological water demand should consider the requirements of different ecological protection objectives. Therefore, different ecological protection objectives should be coordinated in determining that. In the future, the calculation and the multi-objective ecological water demand synergistic method should be studied, and finally the lake ecological water demand that meets different important ecological protection objectives should be determined[14].

\subsection{Research on multi-source regulation based on ecological water demand guarantee}

Due to the extreme sensitivity to climate change, the diversification of climate conditions, the mismatch between the speed of economic development and social needs, and the uneven distribution of water resources in time and space in some regions of our country[15]. The optimal allocation of water resources with multi-source control can guarantee the effective supply of lake water, protect ecological environment and promote the social economic development.The research on the regulation and control of multi-source water supply plays an important role and value in the reasonable allocation of water resources and meeting the needs of regional water resources. It is also a scientific hot spot that many scholars are concentrating on.

\section{Conclusion}

The water demand of the lake ecosystem is an important guarantee for the health of the lake ecosystem. It is the water quantity or water level to maintain the basic structure and important function of lake ecosystem. How to calculate the ecological water demand of a lake has its own characteristics and application scope. The future study of lake ecological water demand should pay more attention to ecological protection target ecological hydrological demand multi-objective ecological water demand coordination and multi-source control based on ecological water demand guarantee and put forward a more reasonable process of lake ecological water demand.

\section{Acknowledgements}

This work was financially supported by Fund of The Key Research and Development Project of The Ministry of Science and Technology-"Theories and Methods of Multi-objective Regulation of Water Resources Under the Condition of Connecting Rivers, Lakes and Reservoirs" (NO. 2017YFC0406001).

\section{References}

1. N.L. Poff, Fresh Water Biology. J. 63, 1011-1021 (2017)

2. P.D. Rashin, E. Hansen, R.M Margolis, Nat. Res. For.J. 20, 1 15 (1996)

3. A J Baird, R L Wilby. Eco-hydrology: Plant and water in terrestrial and aquatic 
environments[J]. London and New York: Routledge Press.1999.

4. Tang Yun, Wang Hao, Yan Denghua [J].]Ecological Water Demand of Wetland in Xianghai Nature Reserve Resource Science, 2005(05):101-106.

5. Ngana J O,Mwalyosi R B,Masulu N F.Development of an integrated water resources management plan for the lake Manyara sub-basin [J].Nothern Tanzania. Physics and Chemistry of the Earth, 2003,1003-1038.

6. Pang Rui, Dong Dianhong. Ecological water demand of lake wetlands in the lower Bayin River Basin[J]. Henan Water Conservancy and South-to-North Water Diversion, 2020, 49(05): 30-31.

7. Zhang Jianyong, Wang Xiaohong, Yang Qing, et al. Study on the Countermeasures of Ecological Water demand guarantee in main rivers and lakes in China [J].China Water Conservancy ,2017(23):8-11+15.

8. Chen Changqing, Wei Cong. Study on the method of determining ecological water level in Lake [J]. Water resources development and management, 2020(02):30-33.

9. Chen Jiang, Duan Ming, Wu Peijun, Sun Jiwan. Study on Ecological Water Level of Poyang Lake [J]. Different Time Scale Jiangxi Water Conservancy Science and Technology (03):160-163.

10. Yu Xiaolong, Xu Hongzeng, Liu Xinyang.Study on Ecological Water level and Water ecosystem Health in Dongping Lake [J]. People's Yellow River, 2019,41(11):59-64.

11. Liu Jingling, Yang Zhifeng. Study on the Calculation Method of Water Demand in Lake Ecological Environment [J]. Journal of Natural Resources, 2002(05):604-609.

12. Xie Yonghong, Li Feng, Chen Xinsheng. Study on the minimum ecological water demand of Dongting Lake[J]. Resources and Environment in the Yangtze River Basin 21(01):64-70.

13. Cui Lijuan, Bao Daming, Xiao Hong, et al. Study on Ecological Water demand of Wetlands based on Ecological Protection goal [J].] World Forestry Research, 2006(02):18-22.

14. Liang Ke, Xu Zhixia, Chu Min, et al. A method for determining ecological protection objectives [J].China Rural Water Conservancy and Hydropower Station 2019(11):9093.

15. Wang Zhonggen, Li Zongli, Liu Changming. A theoretical study on the connection of rivers and lakes [J]. Journal of Natural Resources, 2011,26(03):523-529. 